\title{
BLASFEMIA Y EXPIACIÓN PÚBLICA: LA ORALIDAD DE LA EXCLUSIÓN SOCIAL (SIGLOS XV-XVII)
}

\author{
Martí Gelabertó Vilagran \\ Université de Franche-Comté, Francia
}

RESUMEN: A través del estudio de diversas fuentes civiles y religiosas elaboradas en el transcurso de los siglos XV al XVII (legislación real y religiosa, literatura teológica y de reforma moral...) analizamos la función de las ceremonias públicas de expiación contra blasfemias y juramentos en el marco geográfico peninsular con especial incidencia en Cataluña. Celebraciones expiativas convertidas a veces en instrumento principal para exorcizar los males de una sociedad atenazada por el miedo ante un futuro incierto, frente a la incapacidad de los poderes temporal y espiritual en resolver situaciones de crisis política o social extremas.

Palabras clave: Blasfemia, juramento, religiosidad, Edad Moderna.

\section{BLASPHEMY AND PUBLIC ATONEMENT: THE ORALITY OF SOCIAL EXCLUSION (XV-XVII CENTURIES)}

\begin{abstract}
Through the study of various civil and ecclesiastical sources developed in the sixteenth and seventeenth centuries (real and religious legislation, theological and moral reform literature...) we analyzed the role of public ceremonies of atonement against blasphemy and oaths in the peninsular geographic framework with special emphasis on Catalonia. Expiatory celebrations sometimes converted in main instrument to exorcise the evils of a society gripped by the fear of an uncertain future, against the inability of the temporal and spiritual powers in resolving situations of extreme political or social crisis.
\end{abstract}

Keywords: Blasphemy, oath, religiosity, Modern Age. 


\section{Introducción ${ }^{1}$}

En el siglo XXI la represión contra los blasfemos es una característica común de los Estados islámicos más intransigentes cuyo ejemplo más paradigmático se focaliza en la figura del escritor de origen hindú Salman Rushdie, obligado a vivir en un continuo exilio forzoso por temor a ser asesinado por algún integrista musulmán tras pronunciar el Ayatollach Khomeyni en 1989 una fatua condenándolo a muerte como castigo por escribir Los versículos satánicos, libro blasfemo para el islamismo radical. Periódicamente los medios de comunicación internacionales informan de noticias relacionadas con encarcelamientos y procesos de cristianos en países de fe musulmana acusados de blasfemar contra la religión islámica.

El acoso al libre pensamiento no es exclusivo del mundo religioso musulmán. Sin ápice de comparación, ciertos extremismos espirituales renacen con fuerza en el mundo occidental. En una Europa convulsionada por el avance de los integrismos religiosos de diverso signo, la secularización cede claramente terreno en beneficio de lo espiritual en algunas naciones de indudable tradición democrática en forma de leyes que retrotraen, de manera lejana, a la legislación religiosa medieval. El 1 de enero de 2010 el Parlamento de Irlanda promulgó la "ley de la difamación", destinada a reprimir la blasfemia con multas de hasta 25.000 euros a quien expresara una opinión injuriosa "tremendamente abusiva o insultante en relación a una materia tenida como sagrada por cualquier religión que cause indignación en un substancioso número de seguidores de esa religión" ${ }^{\prime 2}$. Controvertida ley vigente en un país de mayoría confesional en cuya constitución se reconoce la especial posición de la religión católica. Varios países mantienen leyes para castigar a los blasfemos como Finlandia donde puede acarrear incluso la pena de cárcel. Afortunadamente, la mayoría de los países occidentales no hacen uso de sus leyes contra la blasfemia (Dinamarca, Holanda, Canadá, diversos estados de EE.UU...). En Francia y Bélgica no existe desde hace mucho tiempo la represión legal del blasfemo. Alguno como Inglaterra abolió los estatutos anti-blasfemia en marzo de 2008. En España el delito de blasfemia fue retirado del código penal en 1988. No obstante, la jerarquía religiosa promueve de vez en cuando iniciativas para avivar el debate público. En 1998, el episcopado católico alemán intentó reactivar la legislación anti-

1. Este trabajo es fruto de una investigación más amplia beneficiaria de una beca postdoctoral financiada por la Secretaría de Estado de Universidades e Investigación del Ministerio de Educación y Ciencia (EX2004-0257), realizada en la École des Hautes Etudes en Sciences Sociales de París (EHESS), Centre de Recherches Historiques, Groupe d'Etudes Hispaniques, dirigida por el profesor Bernard Vincent.

2. Noticia aparecida en la edición de El País del sábado 2 de enero de 2010. 
blasfema con el pretexto de que ciertos ateos habían declarado a la institución eclesiástica como el criminal más grande de la historia de la humanidad.

Cuestión controvertida por excelencia su carga polémica no se diluye en tiempos pretéritos. Si retrocedemos diversos siglos en la historia cultural europea el tema de las blasfemias es motivo de grave preocupación entre teólogos y confesores de los siglos XVI y XVII. A este respecto, la historiografía europea sobre la materia establece diversos motivos por los que la gente de antaño era tan propensa a jurar y blasfemar ${ }^{3}$.

En la Europa preindustrial domina la figura del blasfemo que maldice por razones culturales y psicológicas. Las blasfemias son a menudo la respuesta cultural inmediata al malestar psíquico de las personas más vulnerables de la sociedad y el habla común de muchos individuos en las celebraciones festivas o de carnaval cuando el alcohol y los bailes desenfrenados desinhibían las lenguas $^{4}$. Las fuentes judiciales del Santo Oficio de los siglos XVI y XVII revelan que la casi totalidad de las blasfemias examinadas por los jueces de los diversos tribunales de distrito españoles eran pronunciadas principalmente por personas de sexo masculino, de carácter vehemente, cuya válvula principal de escape emocional son los insultos acompañados de blasfemias en situaciones de fuerte malestar anímico provocadas por diversos motivos: rabia incontrolable causada por los vapores etílicos del alcohol con frecuencia en el transcurso de acaloradas partidas de juego por la excitación emocional de los jugadores en ver perder su dinero; estrategia verbal como procedimiento para desafiar a un enemigo en defensa del honor ultrajado; lenguaje coercitivo habitual de agresión en las riñas entre familiares, vecinos o foráneos; expresiones de ansiedad y frustración frente a las desdichas de la vida surgidas espontáneamente de la boca de los individuos en el frenesí de los desbordamientos lúdicos; estallidos repentinos de mal humor ante acontecimientos inesperados que conllevaran pequeños accidentes en la calle, el campo o la casa que la costumbre ha banalizado ${ }^{5}$. Las

3. Son esenciales para un buen conocimiento del tema los siguientes textos: Cabantous, A., Histoire du blasphème en Occident, XVle-XIXe siècle, París, 1998; Delumeau, J. (ed.), Injures et blasphèmes, París, 1989; Dartevelle, P., Denis, P. y Rubyn, J., Blasphèmes et libertés, París-Bruselas, 1993; Leveleux, C., La parole interdite: le blasphème dans la France médiévale (XIIle-XVle siècle): du péché au crime, París, 2001; Casagrande, C y Vecchio, S., I sette vizi capitali. Storia dei pecati nel Medioevo, Turín, 2000.

4. Usunáriz, J. M., "Verbum Maledictionis. La blasfemia y el blasfemo de los siglos XVI y XVII", R. G. Bourellier y J. M. Usunáriz (eds.), Aportaciones a la historia social del lenguaje: España, siglos XIV-XVIII, Madrid, 2006, p. 208.

5. Gelabertó Vilagran, M., "Inquisición y blasfemias en la Cataluña de los siglos XVI y XVII", Pedralbes. Revista de història moderna 28 (2008), pp. 651-676; Gelabertó Vilagran, M., "Legislación y justicia contra blasfemos. (Cataluña, siglos XV-XVII), Hispania Sacra LXIV, 130 (2012), pp. 557-561; Blázquez Miguel, J., La Inquisición en Cataluña. El tribunal del Santo Oficio de Barcelona, Toledo, 1990, pp. 231-237; Contreras, J., El Santo Oficio de la Inquisición 
desazones se verbalizan en blasfemias y juramentos contra objetos y personas en el espacio público o privado. En estas situaciones, las injurias, los insultos y los reniegos más impronunciables aparecen por doquier. En la mayoría de casos las blasfemias y juramentos son proferidas sin verdadera intención de ofender deliberadamente a Dios. Tan sólo una minoría de convictos son encontrados culpables de pronunciar blasfemias graves al renegar de un artículo de fe o de un dogma de la religión católica ${ }^{6}$.

En este marco de aplicación nos proponemos analizar a través del estudio de diversas fuentes documentales elaboradas en el transcurso de los siglos XV al XVII (legislación real y religiosa, literatura teológica y de reforma pastoral...) la función de las ceremonias públicas de expiación contra blasfemias y juramentos en el marco geográfico peninsular con especial incidencia en Cataluña. Celebraciones expiativas convertidas a veces en instrumento principal para exorcizar los males de una sociedad atenazada por el miedo ante un futuro incierto, frente a la incapacidad de los poderes temporal y espiritual en resolver situaciones de crisis política y social extremas.

\section{Blasfemia y confesionalización: el control eclesiástico de la palabra transgresora}

El término blasfemia procede etimológicamente del verbo griego blaptein (dañar, perjudicar) y del vocablo phène (palabra). La blasfemia es la palabra o expresión injuriosa dirigida contra Dios, la Virgen María, los santos o las cosas sagradas en su relación de dependencia hacia el Creador ${ }^{7}$. La blasfemia puede ir acompañada de juramentos. En expresión del lingüista francés Emile Benveniste el juramento es "la manifestación blasfematoria por excelencia" ${ }^{8}$. El

en Galicia, Madrid, 1982, pp. 555-559; Zintzo-Garmendia, B., "Actividad habitual del tribunal vasco-castellano", F. Rodriguez de Coro y C. Gómez (eds.), Los Inquisidores, Vitoria, 1993, pp. 220-222; Blázquez Miguel, J., La Inquisición en Castilla-La Mancha, Madrid, 1986, pp. 133 y ss; García Ivars, F., La represión en el tribunal inquisitorial de Granada, 1550-1819, Madrid, 1991, pp. 159-161; Haliczer, S., Inquisición y sociedad en el reino de Valencia (1478-1834), Generalitat Valenciana, 1993, pp. 435 y ss; Bombín Pérez, A., El tribunal de Logroño (1570-1610), Universidad del País Vasco, Vitoria, pp. 134-138; Boeglin, M., "Blasfemia y herejía en la Época Moderna. Los blasfemos ante la Inquisición de Sevilla en tiempos de los Austrias", Á. Castro Sánchez (coord.), Franciscanos, místicos, herejes y alumbrados, Sevilla, 2010, pp. 283-304; Santana Molina, M., El delito de blasfemia en el tribunal inquisitorial de Cuenca, Publicaciones de la Universidad de Alicante, 2004, pp. 101-103; Lefranc, M. G., Blasphèmes et blasphèmateurs dans le royaume de Valence aux XVIe et XVIle siècles, Toulouse, 1976.

6. Haliczer, S., Inquisición y sociedad... p. 470.

7. Hoareau-Dodinau, J., "Le blasphème au Moyen Âge. Une approche juridique", Atalaya. Revue française d'Etudes Médiévales Hispaniques 5 (1994), p. 195.

8. Benveniste, E., "Blasphémie et euphemie", Problèmes de linguistique générale, Vol. II, París, 1974, p. 254. 
vocablo "juramento" proviene del latín iuramentum, "afirmación o negación de alguna cosa, poniendo por testigo a Dios, o en si mismo o en sus criaturas" ${ }^{\prime \prime}$. El juramento se pronuncia ante los hombres para confirmar la verdad de lo que se afirma y solemnizar la garantía de una promesa.

La escolástica medieval elabora un discurso sobre la blasfemia que descansa en dos definiciones no excluyentes. La primera está influenciada por la visión tradicional de San Agustín formulada en el siglo $\mathrm{V}$ que define las blasfemias como cosas falsas en su vinculación a Dios. La segunda, derivación teológica de la anterior, es elaborada por Santo Tomás de Aquino (1224-1274) en su magna obra Summa Theologiae, compuesta durante los últimos años de su vida ${ }^{10}$. Para el Doctor Angélico la blasfemia es un pecado de infidelidad (infidelitas) al mismo Dios por oponerse a la virtud teologal de la confesión de la fe, comportando potencialmente un delito de herejía al negar explícitamente un dogma cristiano. Santo Tomás establece una clara dicotomía entre la blasfemia simple y la blasfemia herética. La primera es aquella que no se opone a la fe, pero desea o impreca a Dios algún mal, como decir: maldito sea Dios; pese a Dios o expresiones semejantes. La segunda manifiesta un error interno con carácter de herejía, opuesto a la fe, palabras que proceden del odio e infidelidad del cristiano hacia al Creador, como decir: Dios no es sabio; reniego de Dios ${ }^{11}$. En realidad esta clasificación daba pábulo a muchas confusiones entre teólogos e inquisidores a la hora de interpretar el supuesto carácter herético de cualquier blasfemia $^{12}$. No obstante, Santo Tomás exculpaba del pecado de blasfemia cuando la persona que la pronunciaba no fuera responsable de sus actos, ya fuese por locura o enajenación mental transitoria provocada por un acontecimiento o circunstancia que le impidiera calibrar conscientemente la verdadera gravedad de la frase enunciada. Expresado en otros términos, el santo italiano establecía una distinción entre el blasfemo que profería injurias llevado por un sentimiento irrefrenable de furia pasajera, inconsciente del alcance de sus palabras, de la del blasfemo reflexivo con intención expresa de atacar los dogmas o artículos de fe cristianos. Esta conceptualización del fraile dominico sujetará las conciencias de teólogos y juristas católicos hasta bien avanzado el siglo XVIII.

El combate contra las blasfemias se enmarca dentro de un amplio proyecto de sacralización de la sociedad emprendido por las Reformas católica y protestante,

9. Definición del Diccionario de la Real Academia Española, Vol. I, Espasa-Calpe, Madrid, 1984, p. 80.

10. Barbado Viejo, F., (ed.), Summa Theologiae, Madrid, 2010 (Parte II, Cuestión XIII).

11. Santa Teresa, M., Compendio moral salmaticense según la mente del Angélico Doctor, Vol. I, Pamplona, 1805 (Tratado X, Capítulo IV, pp. 297-300).

12. Caro Baroja, J., El Señor inquisidor y otras vidas por oficio, Madrid, 1986, p. 25. 
especialmente a partir de las últimas décadas del quinientos ${ }^{13}$. La costumbre inveterada para muchos cristianos de maldecir a todas horas y al menor contratiempo a Dios y a toda su corte celeste era una práctica cotidiana transmitida a través de generaciones. El proceso de moralización social iniciado por las autoridades religiosas postridentinas tiene como uno de sus principales objetivos extirpar de los hábitos corrientes de la gente el pernicioso vicio de blasfemar. La Iglesia enseñará a los feligreses a controlar los desbordamientos emocionales causados por la desesperanza o la cólera a que daban lugar los infortunios diarios de la vida verbalizados mediante reniegos y juramentos. La distancia jerárquica entre Dios y los hombres no podía ser violada, las blasfemias y las injurias, bien al contrario, introducían un factor de peligrosa familiaridad entre los cristianos y el Creador.

El clero reformador muestra un especial interés en moralizar la vida interna de las familias, uno de los principales bastiones reproductivos de las más infamantes blasfemias dirigidas al cielo. Fray Luis de Granada (1504-1588) apremia a la moralidad de la parentela familiar: "Tenga, pues, el buen cristiano cuidado que los que tiene en su casa estén libres de vicios conocidos, como son enemistades, juegos, perjuros, blasfemias y deshonestidades"14. El cabeza de familia debe dar ejemplo de rectitud moral e intachable conducta sobre el que mirarse el resto de los miembros del núcleo familiar. Los hijos no deben escuchar jamás de los labios de su progenitor exclamaciones soeces ni insultos injuriosos contra la providencia divina o el prójimo. En las disputas entre padres e hijos se cruzaban a menudo acusaciones con juramentos difamatorios hacia Dios. En la Cataluña moderna era un comportamiento de lo más habitual. Los progenitores chillaban: "Com Deu esta en el cel quet tinch de trencar las camas" "Como Dios está en el cielo tengo que romperte las piernas"), "Per aquesta cara de Deu que no me la portaras al moli" ("Por esta cara de Dios que no me la llevarás al

13. Algunos teóricos eclesiásticos eran incluso partidarios de llegar a las soluciones más radicales para terminar con la costumbre de blasfemar. En una obra dedicada a la guerra marítima publicada en Coimbra en 1555, su autor, Fernando de Oliveira, humanista luso, profeso en la Orden de los dominicos, expone su concepción de la "guerra justa", y de modo simultáneo critica violentamente la trata de esclavos que junto al comercio del oro y de las especias constituía la base de la economía portuguesa. Según sus razonamientos, las blasfemias son por si mismas casus belli, y motivo legítimo por el que las naciones deben ir a la guerra, junto a otras dos importantes razones. El religioso portugués las enumera por orden de importancia decreciente: 1. "Castigar las injusticias cuando el que las comete no las quiere reparar".

2. "Defender su pueblo de aquellos que la atacan injustamente y así impedir a los malvados hacer el mal". 3. "Hacer la guerra a los que ofenden a Dios por las blasfemias y las herejías y a aquellos que prohiben la predicación y persiguen a los convertidos" (Callier-Boisvert, C., "Captifs et esclaves au XVle siècle. Une diatribe contre la traite reste sans écho", L' Homme 38,145, p. 122).

14. Fray Luis de Granada, Guía de pecadores, en la qual se trata copiosamente de las grandes riquezas y hermosura de la virtud y del camino que se ha de seguir para alcanzarle, Biblioteca Virtual Miguel de Cervantes, Alicante, 2008. 
molino") , "Ja rebentasses de pur amor de Deu" ("Ya reventases de puro amor de Dios), "No vindrà un dimoni y seten portara" ("No vendrá un demonio y se te llevará"). Y los hijos maldecían a los padres con acritud: "Malehit siau vos, anausen al diable" ("Maldito seáis, iros al diablo") ${ }^{15}$.

La disciplina moral debe extenderse al personal doméstico del hogar, si es que lo hubiere, proclive a dejarse arrastrar por la rudeza primaria de sus instin$\operatorname{tos}^{16}$. Los reformadores señalan a las mujeres como las principales responsables de que a todas horas se escuchen maledicencias en las casas y en otros muchos lugares a causa del particular carácter femenino, inestable y neurasténico por naturaleza. El jesuita Agustín Ramírez y Orta escribe sobre el asunto en 1688:

Es lástima ver en algunos, quan arraigado está este vicio infame de maldecir. Especialmente en las mujeres, que son iracundas, y tienen gran facilidad en el maldecir...en algunas tan arraigado; que suelen continuar con el, hasta la muerte...Y estas, aunque se acusan de maldiziones graves, no se enmiendan, y se puede dudar, si las tales en las confesiones tienen verdadero propósito. Cada día se acusan de maldiciones, y siempre tienen en la boca las mismas ${ }^{17}$.

La práctica eclesiástica de las indulgencias, apoyada sin fisuras por Roma desde la Edad Media, constituía un poderoso procedimiento destinado a combatir, entre otras muchas cosas, el lenguaje blasfematorio. La indulgencia era una remisión penitencial concedida por la Iglesia a los cristianos destinada a borrar de las almas humanas todos los rescoldos de las penas espirituales causadas por los pecados ya perdonados. Era habitual entonces conceder indulgencias a los fieles que destinasen voluntariamente parte de sus recursos monetarios a sostener económicamente

15. BUB (Biblioteca Universitaria de Barcelona), Explicació dels manaments de la lley de Deu, Ms. 1424, sin numerar.

16. Ciertos autores aconsejaban extremar las medidas de precaución frente a la indisciplina de este colectivo doméstico. En su tratado Miroir de la agronomie. Le théâtre d'agriculure et mesnage des champs, publicado en 1600, su autor, Olivier de Serres (1539-1619), - autodidacta francés, humanista protestante, considerado uno de los padres de la ciencia agronómica- expone a sus lectores los conocimientos de agricultura y los métodos de gestión rural que ha aprendido de sus lecturas y viajes, pero especialmente de la experiencia adquirida en los cuarenta años de gestionar su dominio agrícola. En un párrafo de su libro aconseja a los dueños de las casas implantar un sistema original de vigilancia sobre las personas encargadas del mantenimiento de su morada. Dice que la tradición rural sitúa la cocina en la planta baja de la casa, bajo la habitación del amo, en el primer piso. Esta separación invita a los domésticos a blasfemar y entregarse a excesos que quiebran el buen orden moral, ya que escapan al control visual y auditivo del amo. Para remediar esta situación, propone la construcción de una "anticocina" en el primer piso, situada entre las estancias personales del propietario y el comedor, para así controlar las voces y los actos de sus criados (Diller, G. T., "L'autarcie au Pradel: les deux du paon et celui du maître", Bulletin de I'Association d'Étude sur l'Humanisme, la Réforme et la Renaissance 56 (2003), p. 98).

17. Ramírez y Orta, A., Práctica de cura y misiones, Barcelona, 1688, pp. 153-154. 
los gastos materiales del culto eclesiástico. En el año 1498, el obispo de la diócesis de Lérida, Lluis Milà, otorga una amplia indulgencia a quienes aportasen sustento económico para sufragar los gastos de aquel pobre obispado, agravado por el incendio parcial del templo catedralicio que consumió enteramente la sacristía, y por la necesidad de acelerar las obras de construcción del coro de la catedral. Entre los muchos pecados que la redención espiritual borraba del alma del pecador se contaban las palabras blasfematorias: "Que los pugue absolre los qui han blasfemat de Nostre Senyor Deu e los sants" ("Que se puedan absolver los que hayan blasfemado de Nuestro Señor, Dios y los santos" $)^{18}$.

La lucha contra la costumbre de blasfemar dispondrá a partir de la segunda mitad del siglo XVI de una poderosa arma con la progresiva implantación de las cofradías del Santísimo Nombre de Jesús cuyas primeras fundaciones se remontan a los últimos siglos de la Edad Media ${ }^{19}$. Estas agrupaciones piadosas de laicos y religiosos pretendían combatir la blasfemia mediante una práctica frecuente de los sacramentos y por un incremento de la piedad religiosa. En Barcelona la cofradía fue fundada en 1563, en otros lugares como Mallorca su creación tuvo lugar más tarde, en 1581. Este género de cofradías conocerán una rápida progresión por toda la geografía catalana. Ciertos obispos se esmeraron especialmente en publicar los beneficios de la militancia religiosa de los fieles de sus diócesis en estas piadosas asociaciones. En 1594, Jaume Cassador, a la sazón obispo de Gerona, publica un documento que lleva por título Summari de les indulgecies que guanyen los confrares del Santissim Nom de lesus, tenint la bulla de la Santa Cruzada, ultimament publicada, y ara de nou concedidas, y confirmadas per lo Sant Pare Clement Octau, els 30 de setembre 1594, en cuyo preámbulo se pone de relieve la importancia de la cofradía en su ofensiva espiritual contra los juramentos, maldiciones y blasfemias:

Nomenant moltes vegades a lesus ab devoció nos desvia de juraments, blasfemies, maledictions, y altres paraules vanes, de les quals teniem de donar compte a Deu. Nomenant a lesus ab devoció, corregim la Ilengua dels mals abits y perversas costums y la avesam als bons. Guardemnos tots de juraments, blasfemies, maldicions, y nominar diables ni dimonis, perque ells venen al entorn dels que nomenant, perque lo office del Dimoni es destruyr lo que poden ${ }^{20}$.

18. AHMB (Archivo Histórico Municipal de Barcelona), Bans Municipals i fulls varis impresos, 1498-1714, Sin numerar.

19. En 1430, Fray Diego de Vitoria funda en el convento de Santo Domingo de Valencia la primera cofradía del Santísimo Nombre de Jesús. Por bula especial, el Papa Pío IV aprueba y confirma las cofradías con esta devoción en el año 1564.

20. "Nombrando muchas veces a Jesús con devoción nos desvía de juramentos, blasfemias, maldiciones, y otras palabras vanas, de las cuáles tenemos de dar cuenta a Dios. Nombrando a Jesús con devoción, corregimos la lengua de los malos hábitos y perversas costum- 
En sus ordenaciones se enumeraban las gracias de las que gozarían los devotos que rindiesen veneración al Santo Nombre de Jesús. Se otorgaba a quienes entrasen en la cofradía cuarenta días de perdón, y otros tantos días a los que confesaren y comulgaren; si los cofrades recibían la comunión en la festividad de la Circuncisión del Señor (1 de enero) en la iglesia o capilla designada por las autoridades de la congregación, trescientos cuarenta días de indulgencia; los que convencieran a los blasfemos de trazar la señal de la cruz en tierra y besarla, o hacer limosna, como signos depuradores de su ignominioso acto cada vez que pronunciasen una blasfemia, les serían concedidos cuarenta días de perdón; los blasfemadores arrepentidos de corazón con voluntad sincera de reconciliarse con Dios tenían que hacer el signo de la cruz en el suelo y darle un beso como muestra de penitencia, en recompensa de lo cual recibían por cada vez veinte días de perdón ${ }^{21}$. Pertenecer a esta cofradía representaba poseer el mejor escudo defensivo moral frente a la extendida costumbre social de la gente de la época de pronunciar blasfemias por doquier.

Sobre los mismos años otros obispados españoles también fundaron cofradías dirigidas a luchar contra el lenguaje blasfemo. En 1572 el Arzobispo de Sevilla, Cristóbal de Rojas, manda fundar en la capital hispalense y principales ciudades de la diócesis cofradías del Dulcísimo Nombre de Jesús ${ }^{22}$. Otros episcopados instauran cofradías en los siguientes años: Murcia en $1576^{23}$, Málaga en 1590, Badajoz en 1603, León en 1611. Cádiz en 1630. Las agrupaciones religiosas destinadas a combatir los pecados de la lengua van extendiéndose paulatinamente por todo el orbe católico europeo.

\section{Juramentos y blasfemias en el ordenamiento legislativo real hispano}

Las grandes culturas del mundo pagano antiguo ya invocaban a los dioses, ídolos, elementos y accidentes geográficos naturales (fuego, tierra, montañas, ríos...). Los egipcios juraban por sus dioses, Isis y Osiris; los persas ponían por testigo al sol; los escitas juraban por el aire y por el hierro de sus armas; los atenienses por Minerva; los lacedemonios por Cástor y Pólux; los griegos juraban por Zeus, señor

bres y las dirigimos a las buenas. Guardémonos de juramentos, blasfemias, maldiciones, y de nombrar diablos ni demonios, porque ellos vienen al entorno de quienes los han nombrado, porque el oficio del demonio es destruir lo que pueden" (Bans municipals, sin numerar).

21. Las ordenaciones de la cofradía están incluidas en las páginas de la obra de Santo Tomás, L. de., Excelencias del Nombre de Jesús, y su cofradía contra juradores, blasfemos, y maldicientes, Madrid, 1697.

22. Boeglin, M., "Disciplina religiosa y asentamientos de la doctrina: el delito de proposiciones ante la Inquisición de Sevilla", Historia, Instituciones, Documentos 30 (2003), p. 141.

23. Montajo Montajo, V., "Culto y práctica social: la cofradía del Nombre de Jesús de Murcia", Murgetana, 2008, p. 59. 
de todos los dioses. El pueblo romano dispensaba un verdadero culto al juramento. Ningún ciudadano se consideraba formalmente obligado si no había jurado en nombre de uno de los principales dioses del panteón pagano, Júpiter, Juno, Neptuno, etc. Los hombres juraban generalmente por Júpiter, las mujeres por Juno, el militar por Marte, las doncellas por Diana, el vendimiador por Baco, el labrador por Ceres. Los cónsules, antes de tomar posesión de sus funciones, prestaban juramento en el templo de Júpiter. Los romanos juraban tanto por sus propios dioses y semidioses (Castor, Pólux o Hércules) como por las divinidades foráneas importadas de las distintas culturas religiosas conquistadas militarmente. Normalmente se juraba por más de un dios, y a veces por todos juntos. En la cultura romana jurar equivalía a decir la verdad y cumplir la palabra empeñada. Filósofos y legisladores de la Antigüedad recomendaban que sólo se jurase en los casos y juicios importantes por la consideración moral y legal otorgada al juramento en $\mathrm{si}^{24}$.

En la Edad Media el juramento interviene constantemente en las relaciones de la vida. Los teólogos medievales justifican la importancia del juramento con citas extraídas del Deuteronomio, uno de los libros del Antiguo Testamento:

Procura con diligencia, no olvidarte del Señor, que te sacó de la tierra de Egipto, de la casa de la esclavitud. Temerás al Señor, tu Dios y a él sólo servirás, y cuando hayas de jurar lo has de hacer por su nombre... Temerás al Señor, tu Dios, y a él sólo servirás; con él te unirás, en su nombre harás tus juramentos ${ }^{25}$.

Uno de los grandes Padres de la Iglesia primitiva de Oriente, San Juan Crisóstomo, sostiene en sus consideraciones teológicas que no existe culpa alguna cuando se jura por necesidad, justicia y verdad, pero añade que es muy difícil que concurran estas tres circunstancias para que sea lícito el juramento. El patriarca de Constantinopla dice que el cristiano que jurase sin tener obligación o a la ligera será castigado por Dios en su persona y tampoco le faltarán desgracias merecidas en su casa.

En la España medieval era costumbre jurar poniendo la mano en los sepulcros o altares de santos para que fuesen testigos de la verdad o castigasen el perjurio. A este respecto, existían ciertas iglesias Ilamadas juraderas como la de San Vicente de Ávila, Santa Gadea en Burgos y otras. La tradición decía que la persona que cometía perjuro en aquellos lugares sagrados se le secaba la mano. Una costumbre que se prolongó hasta finales del siglo $\mathrm{XV}^{26}$. Los cristianos de la Alta Edad Media dieron a los juramentos una aplicación ilimitada, incluyén-

24. Voz "juramento", Enciclopedia Espasa-Calpe, Vol. 28, Madrid, p. 3198.

25. Cita en Panizo Rodríguez, J., "Formulas de juramento en la Edad Media", Revista de folklore 140 (1992), p. 69.

26. Panizo Rodríguez, "Formulas de juramento...", p. 70. 
dolos entre las prácticas jurídicas del juicio de Dios y las ordalías, pruebas que servían para averiguar la culpabilidad o inocencia del acusado. Los Reyes Católicos abolieron esta arcaica jurisprudencia pero sin suprimir el juramento de los actos judiciales como prueba y afirmación de la palabra ${ }^{27}$.

Diversos textos literarios españoles de los siglos XII al XV recogen toda una serie de juramentos muy en uso durante aquellas centurias. El juramento más habitual era el que ponía por testigo a Dios y en menor frecuencia a la Virgen María, San Isidoro, San Millán y Santa Ana. En El libro del buen amor, también Ilamado Libro de los cantares, quizás la obra más representativa del Mester de Clerecía $^{28}$, elaborada entre 1330 y 1340, los juramentos más frecuentes son los dirigidos a Dios: "A Dios juro, señora, e por aquesta tierra/Que cuanto vos he dicho, de la verdad non yerrra"29. Gonzalo de Berceo, autor del siglo XIII, uno de los primeros escritores en lengua española, hace lo mismo, en Vida de Santo Domingo de Silos: "Yo nunque alcé propio, nin fiz cosa atal,/adugo por testigo al Padre spirital"30. En La vida de San Millán de la Cogolla hace alusión a un juramento al santo biografiado: "Pusieron e juraron siempre todas razones/a Sant Millán la casa de dar tres pipiones" ${ }^{\prime 31}$. Otro grupo lo integraban los juramentos que ponían por testigos objetos estimados para el hombre medieval como el calzado, la espada y la corona. En El libro de Alexandre, obra en verso de la primera mitad del siglo XIII, que narra la vida de Alejandro Magno adornada con abundantes elementos fabulosos, aparecen referencias a las dos primeras materias: "Clérigos y alonges/çertas y las mongias/non andan a derechas/palas çapatas ${ }^{32} \mathrm{mías} / \mathrm{mal}$ pecado todos/andan en traversias" 33 , "Tuvo Alixandri que era grafit escarnio/que sele toviese una villa mas que Poro e Dario/dixo yo prometo e juro por el mi gladio ${ }^{34}$ que non dexe en ella calleja nin ningun varrio" ${ }^{\prime 35}$. Alfonso Martínez de Toledo, Arcipreste de Talavera o Corbacho, autor emblemático de la literatura medieval castellana del siglo XV, es quien ofrece mayor cantidad

27. Los Reyes Católicos por cédula promulgada en 1498 y recogida también en la ley 67 de las leyes de Toro de 1505 ponen fin legislativo a esta antigua práctica con apercibimiento de severas sanciones: "Mandamos, que ningún juramento, aunque el juez lo mande hacer, o la parte lo pida, no se haga en San Vicente de Ávila, ni en el herrojo de Santa Agueda, ni sobre altar, ni cuerpo santo, ni sobre las reliquias del cuerpo de San Isidoro de León, ni en otra iglesia juradera; so pena de diez mil maravedíes para la nuestra Cámara y Fisco al que jurare, y al juez que lo mandare, y al que lo pidiere y demandare" (Novísima Recopilación de la leyes de España, Madrid, 1805, ley 5, tit. 7, lib.4, pp. 198-199).

28. Literatura medieval compuesta por clérigos.

29. Cita en Panizo Rodríguez, "Formulas de juramento...", p. 70.

30. Cita en Panizo Rodríguez, "Formulas de juramento...", p. 70.

31. Cita en Panizo Rodríguez, "Formulas de juramento...", p. 70.

32. Çapata: pieza antigua de calzado que llegaba a media pierna.

33. Cita en Panizo Rodríguez, "Formulas de juramento...", p. 70.

34. Espada.

35. Cita en Panizo Rodríguez, "Formulas de juramento...", p. 70. 
de juramentos a Dios, la Virgen María, los Evangelios, la pasión de Cristo, los santos del cielo, etc. Al hablar del segundo mandamiento dice:

Pues, demandándote, por Dios, quál es el que por tal vía de loco amar anda e bive que, non una, mas ynfinidas vezes juró e jura el nombre de Dios en vano, faziendo mill maneras de juramentos, diziendo: Juro a Dios e a Santa María e para estos Santos Evangelyos, e aun para los santos de paraíso, que no te faré e te contesceré. Non dubdes desto, que bien sabes que cristiano $\mathrm{so}^{36}$.

Para la Iglesia el incumplimiento de un juramento equivale siempre a cometer perjurio y a blasfemar. En la sociedad cristiana medieval Dios es el testigo de los juramentos ya que la naturaleza humana es demasiado débil como para garantizar por si misma el cumplimiento de todo aquello que jura ${ }^{37}$. En el decreto de Graciano $^{38}$ se establece que el falso juramento es un pecado mayor que el homicidio, pues quien mata a otro destruye su cuerpo, pero quien perjura destruye su alma. Frecuentemente el perjurio se acompaña de sanciones. Un canon de un sínodo provincial catalán de 1292 titulado "De perjuris", multa a los infractores con 20 morabatins $^{39}$. El poder real también castigaba a los perjuros. Alfonso VIII de Castilla (1155-1214) promulgó medidas legislativas contra los falsos juramentos. En el siglo XV, Enrique III (1379-1406) decretó multa de seiscientos maravedíes para el cristiano que jurase en falso sobre la cruz y los santos evangelios ${ }^{40}$.

Si los juramentos se acompañaban de blasfemias se castigaban con penas físicas. En 1462, el rey Enrique IV dicta una ley en la ciudad de Toledo por la que se castigaba a los blasfemadores a recibir cien azotes, amputación de la lengua y la confiscación de la mitad de sus bienes en beneficio de la Corona ${ }^{41}$. Los Reyes Católicos en las Cortes de Madrigal de las Altas Torres de 1476 añadieron a la antigua ley la potestad de que cualquier persona que oyere blasfemar de Dios o de la Virgen María pudiere prender al infractor por la fuerza y conducirlo a prisión para rendir cuentas ante la justicia de la afrenta cometida ${ }^{42}$. Los mismos monarcas dieron otra vuelta de tuerca represiva a la legislación por la pragmática promulgada en Valladolid en 11 de julio de 1492 donde se establecen los castigos a aplicar en función de la condición social de los blasfemos:

36. Cira en Panizo Rodríguez, "Formulas de juramento...", p. 70.

37. Carrasco Manchado, A. I., "Palabras y gestos de compromiso: los reyes castellanos y sus juramentos (siglo XV), e-Spania 4, diciembre de 2007.

38. Monje y canonista italiano del siglo XII, autor de una importantísima colección de cánones y constituciones pontificias que forman la primera parte del Corpus luris Canonici.

39. En lengua castellana maravedí o maravedís.

40. Novísima Recopilación... libro XII, título VI, ley I, p.320.

41. Novísima Recopilación... libro XII, título V, ley II, p. 317.

42. Novísima Recopilación... libro XII, título V, ley III, pp. 317-318. 
Mandamos y defendemos, que ningunas personas de nuestros Reynos, de qualquier estado, condición, preeminencia o dignidad que sean, no sean osados de decir, descreo de Dios y despecho de Dios, y mal grado haya de Dios, ni ha de poder en Dios, ni pese a Dios; ni lo digan de nuestra Señora la Virgen María su Madre, ni otras tales ni semejantes palabras que las suso dichas en su ofensa; so pena que la primera vez sea preso, y esté en prisiones un mes, y por la segunda, que sea desterrado del lugar donde viviere por seis meses, y mas que pague mil maravedís, la tercia parte para el que lo acusare, y la otra tercia parte para el juez que lo juzgare, y otra tercera parte para los pobres de la cárcel del lugar do acaesciere; y por la tercera vez, que le enclaven la lengua, salvo si fuese escudero, o otra persona de mayor condición, que la pena sea destierro y de dineros doblada que por la segunda; pero mandamos, que si algún esclavo fuere preso, porque dixere algunas palabras de las suso declaradas, y el dueño del tal esclavo quisiere más que le sean dados cincuenta azotes públicamente, que no tener su esclavo en la cárcel el tiempo de suso contenido, que sea en su elección, y que de estas dos penas aquella se de al dicho esclavo qual su dueño escogiere ${ }^{43}$.

Esta ley fue renovada por Isabel y Fernando en Sevilla en 9 de junio de 1500 y por su nieto Carlos V en 1525 y $1528^{44}$. Felipe II, en 1566, acuciado por las necesidades militares y la imperiosa necesidad de obtener recursos humanos para los múltiples frentes bélicos abiertos en Europa añade a la legislación anterior que los convictos por blasfemia pudieran ser condenados a la pena de diez años en las galeras del rey ${ }^{45}$.

En el siglo XVII el ordenamiento jurídico de la monarquía austracista enriqueció las leyes destinadas a castigar la práctica indiscriminada de jurar de muchos españoles. En 1639, Felipe IV intenta poner límites al extendido hábito de pronunciar juramentos frente a cualquier eventualidad. La normativa establecía que sólo se podía jurar ante los jueces, oficiales de justicia o para validar algún documento notarial. El infractor incurriría la primera vez en una pena de diez días de privación de libertad y veinte mil maravedís de sanción; si reincidía una segunda ocasión el castigo consistía en treinta días de cárcel y cuarenta mil maravedís de multa; una tercera vez se le añadía a la pena anterior cuatro años de destierro en un radio de cinco leguas de la ciudad o pueblo donde residiese, opcionalmente conmutable, a criterio del juez, por prisión equivalente a igual

43. Novísima Recopilación... libro XII, título IV, ley IV, p. 318.

44. Novísima Recopilación... libro XII, título IV, ley VI, p. 318.

45. Novísima Recopilación... libro XII, título IV, ley VII, pp. 318-319. Para un conocimiento más extenso de la cuestión ver el artículo de Heras, J. L., "Los galeotes de la Monarquía Hispánica durante el Antiguo Régimen", Studia Historica Moderna 22 (2000), pp. 288-289. 
tiempo, o prestar servicios en las galeras del rey, siempre y cuando el reo no tuviera bienes con los que responder para hacer frente a la pena pecuniaria ${ }^{46}$. La ley general se extiende en otras consideraciones como que los corregidores e inquisidores del reino sean celosos en la represión de este vicio y no se admita a cargo público alguno de la administración a candidato sobre el que recayera la sospecha de haber proferido juramentos.

De lo expuesto hasta aquí se desprende que en España el período más activo en materia legislativa contra la blasfemia tuvo lugar entre finales del siglo XV y primera mitad del XVI, en los edictos de 1492, 1500, 1525 y 1566 . Alain Cabantous señala que las disposiciones reales dirigidas contra los pecados de la lengua en Europa se inscriben dentro de una estrategia general de actuación, cuyo objetivo era consolidar la autoridad de unas monarquías absolutas todavía débiles en el plano político ${ }^{47}$. En España, las principales leyes contra la blasfemia son legisladas no tanto para reafirmar el potencial autoritario del Estado Absoluto como para resolver situaciones que requiriesen soluciones políticas en coyunturas especialmente delicadas para la religión católica. En este sentido, las pragmáticas publicadas desde fines del siglo XV se enmarcan en la defensa y afirmación del peso del catolicismo frente a las poblaciones conversas de judíos y musulmanes (edicto de 1492), mudéjares (edictos de 1500 y 1525), y calvinistas sublevados de los Países Bajos (edicto de 1566) ${ }^{48}$.

\section{Blasfemia y expiación pública}

Las Sagradas Escrituras y los anales histórico-legendarios medievales registran escalofriantes ejemplos de la sevicia divina ante las blasfemias. Los autores eclesiásticos de la patrística cristiana se apoyan sobre ciertos episodios narrados en la historia sagrada para demostrar a los lectores y al público oyente de los sermones, en que se mencionaban estos sucesos, de hasta donde podía llegar la ira de la venganza divina hacia todo aquel que se atreviese a retar a Dios profiriendo palabras blasfematorias. El Antiguo Testamento explica que Senaquerid, rey de Asiria entre 705 a 681 a.C. acompañado de un formidable ejército se disponía a atacar la ciudad de Judea, gobernada por el rey Exequias durante una de sus numerosas campañas militares. Delante de las murallas defensivas, el monarca invasor desafía al Dios de Israel proclamando que ningún poder divino impedirá el avance de las tropas. En la madrugada de la víspera del ataque, Jehová envía a un ángel de la muerte sobre los campamentos de los enemigos del pueblo israelita y hace perecer en un instante ciento ochenta y cinco mil soldados de sus efectivos

46. Novisima Recopilación... libro XII, título V, ley VIII, pp. 319-320.

47. Cabantous, Histoire du blasphème... p. 72.

48. Cabantous, Histoire du blasphème... pp. 72-73. 
militares, y él mismo es asesinado por sus hijos. En el Nuevo Testamento se lee que el mal ladrón crucificado al lado de Jesucristo blasfemó en la cruz y por ello murió condenado. La tradición cristiana dice que en la mañana del 26 de junio de 363 una flecha atravesó el pecho del emperador romano Juliano el Apóstata poco después de haber blasfemado. Cesar Baronio, cardenal e historiador napolitano (1538-1607), cuenta en los Annales ecclesiastici el trágico final de Olimpo, hereje arriano del siglo IV, afectado de un violento ataque de hidrofobia cuando tomaba tranquilamente un baño, inmediatamente después de blasfemar de la Santísima Trinidad, de la que los arrianos eran feroces enemigos, y se destrozara con sus afiladas uñas los órganos de su cuerpo causándose la muerte. Otra relación de época medieval dice que Nestorio, patriarca de Constantinopla del siglo $\mathrm{V}$ que dio nombre a la herejía nestoriana, blasfemó de la Virgen y como castigo los gusanos le devoraron la lengua. San Gregorio de Tours cita el caso de León de Poitiers, sordo, mudo y loco al instante de blasfemar.

El discurso eclesiástico, por su parte, afirmaba que la muerte y los infortunios graves de la vida eran a menudo expresiones punitivas de la cólera de Dios. Los predicadores enseñaban a los feligreses que los culpables de blasfemar no restan impunes a los ojos de Dios, las maldiciones dirigidas al cielo o aquellas en las que se utilizase el nombre de la majestad divina como pretexto, revierten en contra de la familia del blasfemo bajo forma de muertes inexplicables y desgracias incomprensibles. Los desastres y las calamidades eran atribuidos a castigos divinos mandados por el Padre Eterno como señales contundentes del enojo celestial por la disipada moralidad de la que se jactaba abiertamente mucha gente que había recibido el sacramento del bautismo. Un predicador capuchino advertía sobre este particular a su auditorio:

Passa avant provocant la ira de un Deu de queus facia sensibles y las suas venganzas. La mort de aquella filla tua, de aquell cap de bestiar, de ahont que ha tingut origen, sino de aquella maledicció quels donarés, de aquella imprecació contra de ella. La desgracia, los infortunis de la casa, tot prové de las tuas malediccions, diu lo profeta Zacarias ${ }^{49}$.

Trono y altar atribuían comúnmente las desgracias que padecía la nación a la impiedad manifiesta de muchos cristianos, responsables de atraer hacia el país todo un cúmulo de infortunios enviados por Dios en forma de acontecimientos extraordinarios como devastadoras pestes, catástrofes meteorológicas,

49. "Pasa antes provocando la ira de un Dios del que os hacéis sensibles a las venganzas. La muerte de una de tus hijas, de aquella res, de donde piensas que ha tenido su origen, sino en aqueIla maldición que pronunciaste contra ella. La desgracia, los infortunios de la casa, todo procede de tus maldiciones, dice el profeta Zacarias" (APPC. Archivo de los Padres Capuchinos de Cataluña), Sermó de las impaciencias y las malas paraulas, Pliego suelto. sin numerar). 
conflictos bélicos o terremotos. Las transgresiones a la moral cristiana de un segmento de la población por su mal hablar exponía a un riesgo elevado de peligro de muerte a todo el conjunto del resto de los buenos cristianos por la relajación del poder civil en erradicar las conductas inmorales de estas personas que se atrevían a desafiar abiertamente con sus blasfemias las normas establecidas por la Iglesia.

Desde el siglo XV las autoridades reales del continente publican leyes destinadas a la represión de los pecadores escandalosos que con su moral corrompida arrastraban a las naciones al caos social. En 1423, el monarca de Portugal, Juan I, insiste de nuevo en la necesidad de aplicar rigurosos castigos para preservar a la sociedad de "fames" ("hambres"), "pestilencias" y "terramortos" $(\text { "terremotos" })^{50}$. Esta ley real será renovada en 1427 bajo el reinado del mismo soberano. En Francia, Luis XI señala en el preámbulo a la ordenanza contra blasfemos, publicada el 12 de marzo de 1478, la prohibición de jugar en determinados lugares y horas de la noche por los tumultos nocturnos que se organizan y la facilidad de blasfemar de la gente allí reunida, causa más que justificada para que la divina providencia envíe una avalancha de sufrimientos al reino impío ${ }^{51}$. Diversos sucesos de especial gravedad acaecidos en la península ibérica ilustran fehacientemente como la blasfemia y la impiedad religiosa de los españoles provocaba la ira de Dios en forma de enormes calamidades.

Entre febrero de 1427 y junio de 1428 Cataluña sufrió una serie de violentas sacudidas sísmicas que provocaron la desolación material y sembraron el pánico entre los habitantes del territorio. La inmensa parte del subsuelo de la geografía catalana estuvo en agitación constante durante meses, inmersa en un proceso que los sismólogos Ilaman "borrasca sísmica". El sábado 15 de marzo de 1427 un devastador terremoto afectó especialmente las comarcas del interior de Gerona. Ciudades como Besalú y Olot fueron literalmente borradas del mapa a las once de la noche de aquel infausto día. La casi totalidad del norte y centro de Cataluña conoció con más o menos rigor la embestida furiosa del movimiento sísmico. En los siguientes días se sucedieron diversas réplicas menos intensas del principal terremoto, hecho que no tranquilizaba en absoluto a la gente $^{52}$. Los batlles ${ }^{53}$ de diversos municipios de Gerona remiten al rey Alfonso V el Magnánimo sendas cartas relatando el caos desbordante y el clima extremo

50. Baquero-Moreno, H., "Injurias e blasfémias proferidas pelo homen medieval portugués na sua vida de relaçao social", Tensoes sociais em Portugal na idade media, Oporto, 1976, p. 85.

51. Baquero-Moreno, "Injurias e blasfémias...", p. 86.

52. Ver capítulo "La seqüència sismica de l'any 1427", C. Olivera, E. Redondo, J. Lambert, A. Riera Melis y A. Roca, Els terratrèmols dels segles XIV y XV a Catalunya, Generalitat de Catalunya, Barcelona, 2006, pp. 85-131.

53. Alcaldes. 
de terror que reinaba en muchas localidades gerundenses tras el gran terremoto. En las misivas se informaba al soberano de la celebración de solemnes procesiones penitenciales acompañadas de jornadas de severos ayunos para implorar la ayuda intercesora de la Virgen María y de San Narciso, patrón protector de la diócesis, a fin de solicitar el amparo celestial para terminar con el flagelo que aniquilaba infinidad de bienes materiales y vidas humanas:

En continent, Senyor, que los dits terratremols hic continuarem, lo clero e totes les gents ab gran contricció, son recorregudes a la misericordia de Nostre Senyor Deu, continuant de nits e de dies solemnes processons, ab deiunis e longues oracions e ab plors e llagrimas, per les quals orehem placada per la intercessió de Madona Santa Maria e del gloriós cos sant de Mossen Sant Narcís ${ }^{54}$.

Las autoridades del Principado se encontraban totalmente desbordadas por la magnitud grandiosa de la catástrofe que arrasó ciudades y pueblos enteros de la geografía catalana. Durante los siguientes días y semanas se sucedieron en Cataluña las prácticas expiatorias públicas de arrepentimiento y reconciliación con el Altísimo de las que participaba el clero local y todas las clases sociales. Las procesiones incorporaban a su aparato escénico las figuras de penitentes descalzos arrastrando pesadas cadenas con los brazos atados a sus espaldas, implorando a gritos la misericordia de Dios, autoflagelantes disciplinándose con látigos de púas hasta desgarrarse las carnes, exposición de las reliquias más veneradas en un ritual colectivo destinado a purificar a la comunidad del pecado ${ }^{55}$. En la capital catalana se organizaron tres grandes manifestaciones procesionales (17 y 19 de marzo, 6 de junio de 1427) con la asistencia de más de tres mil personas ${ }^{56}$.

Como sucedía habitualmente en los casos de crisis inexplicables, el poder civil y el religioso buscaron la responsabilidad directa de la desgracia en personas físicas que desempeñasen la función de chivos expiatorios de las calamidades incomprensibles para neutralizar los temores de una sociedad desamparada y atemorizada, individuos a los que se les pudieran achacar las culpas de la situación anormal vivida por mantener un comportamiento que desagradaba a

54. En continente, Senyor, que los dichos terremotos continuaron, el clero y toda la gente con gran contricción, recurrieron a la misericordia de Nuestro Señor Dios, continuando de noche y de día las solemnes procesiones, con ayunos y largas oraciones y con llantos y lágrimas, por las cuales oramos por la intercesión de Madona Santa María y del gloriosos cuerpo de San Narciso (Cita en Vinyes, R., Anglés. Notes històriques, Barcelona, 1973, p. 111).

55. Riera Melis, A., "L'expiació d'una culpa: les catàstrofes naturals a la baixa edat mitjana", L'Avenç. Revista d'història i cultura 280 (2003), pp. 18-21.

56. Fernández-Cuadrench, J., "Les processons extraordinaries a la Barcelona Baixmedieval (1339-1498). Assaig tipològic", Acta Historica et Arhaelogica Medievalia 26 (2005), p. 410. 
Dios $^{57}$. A la hora de escoger los culpables se eximió de toda responsabilidad a las brujería, probablemente porque las autoridades religiosas continuaban sosteniendo la opinión tradicional heredada de San Agustín de Hipona de que semejantes cúmulo de creencias eran simples embustes y fantasías de mujeres con la cabeza desbocada por la imaginación, o simples víctimas de alucinaciones provocadas por Satanás. Las autoridades civiles parecen que tampoco compartían la idea de que las supuestas siervas del diablo tuvieran algún tipo de complicidad en el desencadenamiento de los terremotos, aunque en el ambiente de crispación emocional que se vivía cualquier pretexto era bueno para incitar a la persecución de la disidencia religiosa, cuando el poder civil de la ciudad de Gerona apremiaba a las instancias eclesiásticas a ser más contundentes en la persecución de las herejía ${ }^{58}$. Los judíos también fueron eximidos de tener cualquier relación con la ola de flagelos catastróficos que asolaban el obispado, pese a los graves tumultos y conflictos habidos con la población cristiana en los años anteriores ${ }^{59}$.

La Iglesia y el poder temporal hallaron en el blasfemo la figura sobre la que descargar las frustraciones de la sociedad. La indisciplina del lenguaje se erigió en la causa principal a la que atribuir las desgracias en aquellos meses de intensa zozobra. La antigua legislación medieval contra las blasfemias promulgada en muchos municipios catalanes en el transcurso de siglos XIII-XIV es nuevamente renovada durante el bienio 1427-28 ${ }^{60}$. Así, las autoridades municipales de Gerona tomaron en seguida el acuerdo de castigar al blasfemo a recibir treinta azotes la primera vez en la plaza pública. Si reincidía, sería azotado sin conmiseración caminando a pies descalzos por las principales calles de la localidad. Si pese a estos severos correctivos no escarmentaba del vicio de blasfemar, se le flagelaría sin compasión hasta que se le abriesen las carnes y se procedería a horadar la lengua con un garfio ${ }^{61}$. Otros municipios catalanes adoptaron idénticas medidas represoras contra los blasfemadores tras el gran terremoto de 1427 . El

57. Riera Melis, A., "Catàstrofe, pànic i ritualitat a la baixa edat mitjana. La resposta de la societat catalana als terratrèmols de 1427-1428", Afers: fulls de recerca i pensament 69 (2011), pp. 375-408.

58. Sobre este asunto los ediles del consistorio gerundense mandaron una carta al rey protestando por la lentitud demostrada por Pere Bramon, delegado del inquisidor, en instruir el correspondiente proceso judicial contra la mujer del panadero Guillem Devesa, acusada de invocar a las fuerzas diabólicas y de realizar sacrificios en su honor (Riera Melis, A., "Catàstrofe i societat a la Catalunya medieval: els terratrèmols de 1427-28", Acta Historica et Archaelogica Medievalia 20-21, 1999-2000, p. 719).

59. En 1413, ataque al call (barrio judío) de Gerona; 1415, el Papa ordena el cierre de la sinagoga judía; 1418, durante la Semana Santa el call es nuevamente atacado por cristianos exaltados; 1419, los judíos consiguen que la sinagoga, clausurada cuatro años antes, sea reabierta.

60. Gelabertó,"Legislación y justicia...", pp. 538-542.

61. Riera Melis, "Catàstrofe i societat...", p. 722. 
20 de marzo el municipio de Cervera prohibe las blasfemias, los juramentos y el juego de dados por considerarse una práctica lúdica que derivaba en frecuentes imprecaciones sacrílegas ${ }^{62}$. Al día siguiente, Manresa aprueba una disposición legislativa semejante ${ }^{63}$. El 23 de abril la localidad de Terrassa sigue los mismos pasos con la aprobación de una severa ley contra la blasfemia ${ }^{64}$. En los primeros días de mayo Barcelona se suma a la serie de municipios catalanes en dictar duras leyes contra los blasfemos ${ }^{65}$. Finalmente, el monarca Alfonso el Magnánimo condena formalmente la blasfemia el 6 de mayo de $1427^{66}$. Simultáneamente, el clero aprovechó la coyuntura catastrofista de los tiempos para presionar al brazo secular a fin de que promulgase una legislación represora que incluyera al resto de los principales vicios a los que tan aferrados estaban los católicos de entonces: el juego de naipes y dados; las relaciones extramatrimoniales; el concubinato; la prostitución; la no observancia del descanso dominical y las jornadas festivas dispuestas en el calendario cristiano ${ }^{67}$. Sin embargo, todo este arsenal legislativo represor parece que no surtió el efecto deseado ya que Dios continuaba haciendo temblar la tierra en los terrenos destrozados por los seísmos con más ímpetu si cabe.

El terremoto más devastador tuvo lugar el día de la Candelaria (2 de febrero) de 1428 a las ocho de la mañana, cuando un temblor de tierra excepcional causó cerca de mil muertos, innumerables heridos, y la destrucción completa de decenas de pueblos del prepirineo catalán, especialmente de las comarcas interiores de la Garrotxa, Ripollés y Cerdanya, aunque sus repercusiones se hicieron notar en toda Cataluña con efectos más o menos importantes. En aquel día y en aquella hora mucha gente se encontraba congregada en las iglesias para participar de la festividad con la asistencia al oficio de la misa, cuando de repente los objetos y mobiliario de los templos empezaron a temblar fuertemente, hecho que provocó una estampida masiva con muchos fallecidos y heridos aplastados por la marea humana. En Barcelona se desplomó súbitamente el rosetón de la fachada principal de la basílica de Santa María del Mar, justo en el instante de mayor concentración de fieles a las puertas del templo que huían asustados de las acometidas del fenómeno natural, causando la muerte de veinticinco personas $^{68}$. Los anales históricos de la época explican como los habitantes de

62. Riera Melis, "Catàstrofe i societat...", p. 721.

63. Riera Melis, "Catàstrofe i societat...", p. 722.

64. Riera Melis, "Catàstrofe i societat...", p. 722.

65. Riera Melis, "Catàstrofe i societat...", p. 722.

66. Riera Melis, "Catàstrofe i societat...", p. 723.

67. Riera Melis, "Catàstrofe i societat...", p. 723.

68. Duran Sanpere, A., Llibre de les solemnitats de Barcelona, Vol. I, Barcelona, 1930, pp. 39-40. 
Barcelona abandonaban precipitadamente la ciudad presos de pánico hacia la vecina sierra de Collcerola ${ }^{69}$.

En realidad sabemos poco del alcance real y el efecto disuasorio que tuvo la política represiva contra las indisciplinas de la lengua y las medidas de consuelo moral destinadas a tranquilizar a una población atemorizada por las sacudidas telúricas Seguramente a medida que transcurría el tiempo y los seísmos cesaron de golpear la tierra, las estrictas leyes dirigidas a los blasfemadores empezarían a relajarse en su aplicación al desaparecer la grave causa que las originó.

La historia proporciona otros preciosos ejemplos de como la incapacidad de los gobernantes del momento se justifica por razones morales en la argumentación de que los desastres naturales y/o políticos son consecuencia de la voluntad punitiva de Dios contra las lenguas blasfemas ${ }^{70}$. Ciertos sucesos acaecidos en el transcurso de los siglos XVI y XVII y que resultaron funestos para los intereses del Estado español son representativos de la sensibilidad religiosa de la época.

En 1541, Carlos V intenta de nuevo tomar Argel, y para ello se organiza una gran expedición naval en La Spezia ${ }^{71}$. Su fracaso será conocido como el Desastre de Argel. En España se concebíó la empresa militar como una guerra divina. Era la causa de Dios contra los infieles musulmanes y se depositaron las fundadas esperanzas de victoria en la providencia celestial que regía los vien-

69. Ver capítulo "El terratrèmol del 2 de febrero de 1428", Els terratrèmols... pp. 135-193.

70. Ciertos episodios de la historia de Europa revelan la importancia que para las autoridades civiles representaba la blasfemia como amenaza real para la seguridad colectiva. Desafiar a Dios con el uso de la palabra soez desencadenaba la venganza divina que era imprescindible conjurar con la adopción de medidas contundentes. El caso de Venecia es ilustrativo. El 29 de agosto de 1500 los turcos ocupan la ciudad de Modon en la costa griega. Enseguida se promulgan leyes agravando las penas sobre blasfemos y sodomitas. En agosto de 1537 Corfú es asediada por las tropas otomanas, un mes después la situación es militarmente insostenible sobre toda la región. El 29 de diciembre el Consejo de la República acuerda crear con carácter de urgencia una magistratura especial encargada de reprimir el delito de blasfemia Gli executori contra la bestemmia. A partir de entonces los blasfemos tuvieron que pasar por dos tribunales: el de la Inquisición y el recién creado por el gobierno de la ciudad. En febrero de 1695, un pavoroso terremoto sacude Venecia. En 10 de marzo se publica un edicto reforzando la legislación coercitiva sobre los blasfemadores (Delumeau, J., La peur en Occident. Une cité assiégée (XIVe-XVIIle siècles), París, 1978, pp. 523-524). Algunos monarcas franceses estaban convencidos que la blasfemia conducía al caos social más absoluto. Tras el desatre militar de las tropas fracesas al mando del rey Francisco I frente al ejército imperial de Carlos V en la batalla de Pavia en 24 de febrero de 1525 se hace recaer la responsabilidad de la derrota y de todas las calamidades del reino a la extendida costumbre de los parisinos en blasfemar. En 1528 el mismo monarca atribuía las guerras, pestes y sequías que arrasaban el país a la perversidad de los blasfemos (Cabantous, Histoire du blasphème... p. 71).

71. Ciudad de la región de Luguria, en el norte de Italia y capital de la provincia de idéntico nombre, situada en el Golfo de La Spezia. 
tos y las tempestades ${ }^{72}$. El fiasco de la aventura norteafricana se atribuyó a un castigo del cielo enviado al país por su moral relajada y la tolerancia mostrada con los blasfemos.

En vísperas de la entrada en combate de la Armada Invencible en 1588, Felipe II dispuso a través de la publicación de un real mandato que los súbditos de su reino se entregasen al recogimiento y la vida austera, los religiosos aumentaran el número y la frecuencia de las misas y rezos, ordenando a las autoridades municipales de Madrid estuviesen especialmente vigilantes para evitar los excesos sexuales que tenían lugar habitualmente en los jardines del Prado, disposiciones cuya finalidad era la de no atraer la cólera divina sobre la nación e hiciera fracasar el plan de invasión. Antes de embarcar para el combate naval, la tripulación recibió la absolución y tanto oficiales como tropa fueron conminados a no blasfemar con la aplicación de severos castigos a los infractores para no poner en peligro el éxito de la empresa. El desenlace de los acontecimientos posteriores es bien conocido. Sin embargo, el período de mayor convulsión político y social corresponde al siglo XVII cuando parece que los españoles dejaron de gozar de los favores de Dios.

La monarquía de Felipe IV (1621-1665) conoció una de las épocas más turbulentas e infaustas de toda la historia de España. A lo largo de aquellos años se encadenaron uno después del otro una serie de sucesos que transformaron el destino de la nación española: guerra en los Países Bajos con el reconocimiento final de la independencia de las Provincias Unidas tras la firma del tratado de Munster en 1648; alianza política y militar de Francia y Cataluña que dará lugar a un prolongado conflicto militar denominado Guerra dels segadors entre los años 1640-1652 por la recuperación del control de aquella porción de territorio peninsular por parte de las tropas castellanas; sublevación en Portugal que terminará definitivamente con la soberanía de la monarquía de los Austrias en aquel reino; conflictos políticos y militares en los territorios italianos con importantes sublevaciones en Sicilia (1646) y en Nápoles (1647): graves disturbios sociales en Andalucía; serios enfrentamientos con Inglaterra por el comercio de Indias. Todos estos frentes abiertos llevaron al empobrecimiento de la hacienda pública estatal, incapaz por si sola de soportar los grandes gastos de las campañas bélicas que se desarrollaban en el interior del país y allende fronteras. El endeudamiento imparable de las finanzas del Estado obligó al gobierno a buscar los capitales necesarios para sufragar los impresionantes consumos monetarios de la administración real en el recurso a la financiación de los banqueros extranjeros. Una circunstancia desfavorable vino a agravar la situación de ruina económica por la que atravesaban las arcas del reino a causa del desplome del

72. Fernández Álvarez, M., El imperio de Carlos V, Madrid, pp. 110-111. 
comercio trasatlántico, especialmente entre 1638 y 1641. Las consecuencias en el plano internacional de todas estas dificultades fueron funestas: pérdidas territoriales muy considerables en Europa y poderío militar notablemente quebrantado. Si la debacle militar y la decadencia política no fueron suficientes, se añadió a las desdichas de la nación el flagelo de la de peste que vino a empeorar aún más la situación crítica por la que atravesaba España. La epidemia de los años 1647-1652 causó estragos sobre todo en la mitad oriental de la península y en Andalucía. El brote epidémico procedente de Argel provocó la muerte de más de medio millón de personas y muchísimas penalidades especialmente entre las clases sociales más humildes y desprotegidas de la sociedad.

La literatura religiosa de la época insistía en la argumentación moral que los pecados humanos estaban en el origen de las desgracias y las guerras. La contumacia de muchos cristianos en Ilevar una vida moralmente disoluta, Ilena de adulterios, blasfemias, robos y homicidios, pese a las reiteradas amonestaciones eclesiásticas, justificaban la venganza de Dios sobre los impíos y sobre aquellos que toleraban o hacían ojos ciegos a los actos de rebeldía dirigidos a la Suprema potestad. Para la Iglesia la guerra era un procedimiento del que se valía el Creador para castigar la soberbia moral y el abandono religioso de las buenas costumbres cristianas de los que se vanagloriaban impúdicamente los españoles. Los ejércitos de las potencias extranjeras enemigas de España en el continente, ya fueran éstas francesas, inglesas u holandesas, eran el brazo armado del que se valía la divina providencia como instrumento apocalíptico para sembrar la destrucción y la anarquía en una tierra cuyos habitantes estaban entregados a la molicie de los peores vicios y entre cuyas preocupaciones principales no estaba precisamente el cultivar la pureza espiritual del alma ${ }^{73}$.

Los monarcas de la casa de los Austrias creían que las guerras y las epidemias que asolaban al imperio español eran castigos enviados por el Padre Eterno. El rey Felipe IV atribuía la causa de muchas de las desdichas padecidas entonces por el país a la mala costumbre de los españoles en jurar públicamente. Así lo reconocía en sendas leyes promulgadas en el bienio 1655-56:

Póngase muy especial cuidado en castigar con demostración a los que incurrieren en el atrevimiento de hacer juramentos públicos contra la Magestad Divina, que sin duda está muy ofendida por las señales de su indignación en los trabajos que se padecen general y particularmente ${ }^{74}$.

73. González Cruz, D., "Los “Dioses" de la guerra: propaganda y religiosidad en España y América durante el Antiguo Régimen", D. González Cruz (ed.), Religiosidad y costumbres populares en Iberoamérica (Actas del I Encuentro internacional celebrado en Almonte - El Rocío, 19-21 de febrero de 1999), Huelva, 2000, pp. 29-49.

74. Novisima Recopilación..., libro XII, título V, ley IX, p. 320. 
Felipe IV manda despachos a cada uno de los obispados del reino en fecha 20 de septiembre de 1662, reconociendo en la misiva que Dios estaba verdaderamente enojado con los españoles por su inveterada costumbre de jurar, de ahí la avalancha de adversidades padecidas por la Corona y sus vasallos en los años precedentes. El monarca pide consejo urgente a la jerarquía eclesiástica acerca de cómo reconciliarse con la majestad celestial y así ponerse a salvo de las represalias divinas que habían golpeado sangrientamente a España desde los inicios de su reinado, y de las que posiblemente les tenía preparadas para un futuro inmediato el Creador. Las medidas adoptadas se conocieron en los meses siguientes. El 23 de noviembre de 1662, el obispo titular de la diócesis de Barcelona, Ramón de Senmenat y de Lanuça, publica un mandato de misión por el que se pone en conocimiento de la población el anuncio de un próximo inicio de una campaña misionera de evangelización en muchas ciudades y pueblos del obispado. En el preámbulo del bando episcopal el prelado menciona el deseo expreso del rey de que se celebraran en todas las parroquias del reino actos de sincera piedad religiosa y de recogimiento espiritual para de esta manera aplacar la ira de Dios e implorar su clemencia para que pusiera término a los padecimientos del país:

Nos Don Ramón de Senmenat y de Lanuça, per la gracia de Deu, y de la Sancta Sede Apostólica, Bisbe de Barcelona, del Consell de Sa Magestat. A tots los faels christians de nostre Bisbat salud en lo Senyor. Fem a saber com la Magestat del Rey nostre senyor Felip IV (que Deu guarde) ab sa Real Carta per Cancelleria despatxadas en Madrid a 20 de setembre proa pasta, desitjos del be publich de sa Monarquia, considerant los castichs tant grans, que los pobles, y vasalls seus en estos anys pastas han patit, y supportat, y pateixen, en guerras, pestes, mort de Principes, y perduas de provincias, atribuint la causa a la facil relaxació de sa virtud, y bons costums, per implorar lo Divini auxili, nos mana, que en tots nostres subdits, procureu llevar los pecats publichs, evitant juraments, y altras ofensas contra la Divina Magestat, movent a tot en arrepentiment y esmena, envien sacerdots tant regulars, com seculars de exemple, y doctrina a fer misión per tot nostre Bisbat, predicant penitencia ${ }^{75}$.

En 1665, año del fallecimiento de Felipe IV y de la desastrosa derrota militar ante los portugueses, se renueva la ordenanza real dirigida a erradicar los juramentos de la vida pública, promulgada una década anterior ${ }^{76}$. Ya bajo la regencia de Mariana de Austria se promulga a 17 de enero de 1666 una nueva

75. ADB (Archivo Diocesano de Barcelona), Registra Gratiarum (1656-1662), Vol. 65, Fol. 238.

76. Novísima Recopilación..., libro XII, título V, ley X, p. 320. 
ley recordando al Consejo de Castilla la obligación de destinar sus esfuerzos a reprimir la práctica cotidiana de jurar entre la gente común para no provocar la ira de Dios, mandato que será renovado por el monarca Carlos II a 3 de octubre de 1670:

El Rey mi Señor (que santa gloria haya) encargó, se castigasen con todo rigor los juramentos y porvidas, así por lo escandaloso de este pecado, como por lo que en ellos se ofende a Dios; y siendo tan justo, que no haga omisión en ello, y que se atienda mucho a la emienda de los pecados públicos; ordeno al Consejo, esté con toda atención a que se observe y cumpla todo el rigor que disponen las leyes, sin que se falte en cosa alguna a ellas, para obligar a nuestro Señor que nos tenga debaxo de su protección y amparo ${ }^{77}$.

Pese a todas estas buenas intenciones, blasfemias y juramentos siguieron gozando de una enorme vitalidad en la práctica oral cotidiana de la gente mucho tiempo después de haberse apagado los últimos rescoldos del Antiguo Régimen.

\section{Conclusión}

Las blasfemias y juramentos se inscriben en el marco de las conductas sociales de una gran parte de la cultura española de la Edad Media y Moderna. Las blasfemias forman parte del lenguaje oral corriente de muchas personas y en lugares de intensa sociabilidad vecinal como tabernas o mesas de juego es el habla dominante para desesperación de los clérigos reformadores. En ciertos acontecimientos extraordinarios los blasfemos se convierten en figuras de exclusión social responsables primeros de los infortunios que flagelan la nación y cuya solución requiere organizar celebraciones expiativas de compunción.

Las ceremonias de expiación públicas se teatralizan a través de la aplicación de castigos ejemplarizantes y la organización de rezos y procesiones colectivas con los que neutralizar al enemigo espiritual imaginario representado en la figura del blasfemo. Estrategia emprendida por las jerarquías civil y religiosa para hacer frente a graves crisis políticas y sociales (guerras, catástrofes naturales, hambrunas...) cuando los recursos de las instituciones son insuficientes y se hace imprescindible acudir a procedimientos extraordinarios. En España son poco frecuentes la celebración de actos expiativos que atribuyan la responsabilidad de los padecimientos de la sociedad exclusivamente a los blasfemos. Con los datos actuales, solo se contabiliza una respuesta contundente del poder civil en el caso de los devastadores terremotos que asolaron Cataluña en el primer

77. Novísima Recopilación..., libro XII, título V, ley X, p. 320. 
tercio del siglo XV cuando se promulgaron duras leyes contra los blasfemadores. Hasta la larga crisis política internacional e interna de la sociedad española de mediados del siglo XVII no encontramos una campaña expiativa organizada por el Estado que abarque al conjunto de la nación y que atribuya explícitamente a los blasfemos la culpabilidad de los males que desgarraban España. No obstante, no se llegaron a promulgar leyes especiales que agravaran las penas sobre los convictos por blasfemia ni en los momentos más difíciles de la crisis, al contrario de lo que sucedía en otras partes del continente europeo. Sólo en contados casos los poderes temporal y espiritual recurrieron a la organización de actos penitenciales colectivos para paliar sus propias insuficiencias y debilidades.

Ello no era óbice para que la Iglesia siguiera organizando celebraciones expiatorias a pequeña escala a lo largo de los siglos y hasta nuestros días. El sábado 14 de noviembre de 2013 tuvo lugar en la parroquia de Santa María de Gracia de Barcelona un acto público de reparación a Nuestra Señora de Montserrat, patrona de Cataluña, por la blasfemia realizada por la empresa Caganer.com. Esta sociedad fabricante de figuras de belén tuvo la ocurrencia de comercializar la santa efigie de la Virgen en posición de defecar como una figura más del repertorio de caganers ${ }^{78}$. La Asociación de Jóvenes de San José, una de las promotoras del acto, convocaba a todos los católicos de Cataluña a participar y en un comunicado de prensa señalaba que "esto atenta contra Dios y el Cielo y es necesario realizar un acto público de desagravio a Nuestra Madre y Patrona la Virgen de Montserrat para pedir perdón por las ofensas recibidas de forma pública". El evento aglutinó a un buen número de asistentes.

78. Caganer: Figura del pesebre catalán que representa a un personaje excretando las heces corporales. Tradicionalmente el caganer era un campesino ataviado con la típica indumentaria catalana (faja y barretina), colocado discretamente en un rincón del belén oculto bajo un arbusto y haciendo sus "necesidades". Modernamente se han introducido versiones del caganer con las imágenes de personajes populares como políticos, deportistas o artistas. 